\title{
Solar irradiance during the last 1200 years based on cosmogenic nuclides
}

\author{
By EDOUARD BARD ${ }^{1 *}$, GRANT RAISBECK ${ }^{2}$, FRANÇOISE YIOU ${ }^{2}$ and JEAN JOUZEL ${ }^{3}$, \\ ${ }^{1}$ CEREGE, Université d'Aix-Marseille, UMR-CNRS 6635, Europôle de l'Arbois, BP 80, 13545 Aix- \\ en-Provence Cedex 4, France; ${ }^{2}$ Centre de Spectrométrie Nucléaire et de Spectrométrie de Masse, \\ IN2P3-CNRS, 91405 Orsay, France; ${ }^{3}$ Laboratoire des Sciences du Climat et de l'Environnement,
} CEA-CNRS, Orme des Merisiers, 91191 Gif-sur-Yvette cdx, France

(Manuscript received 12 April 1999; in final form 16 September 1999)

\begin{abstract}
Based on a quantitative study of the common fluctuations of ${ }^{14} \mathrm{C}$ and ${ }^{10} \mathrm{Be}$ production rates, we have derived a time series of the solar magnetic variability over the last 1200 years. This record is converted into irradiance variations by linear scaling based on previous studies of sun-like stars and of the sun's behavior over the last few centuries. The new solar irradiance record exhibits low values during the well-known solar minima centered at about 1900, 1810 (Dalton) and $1690 \mathrm{AD}$ (Maunder). Further back in time, a rather long period between 1450 and $1750 \mathrm{AD}$ is characterized by low irradiance values. A shorter period is centered at about $1200 \mathrm{AD}$, with irradiance slightly higher or similar to present day values. It is tempting to correlate these periods with the so-called "little ice age" and "medieval warm period", respectively. An accurate quantification of the climatic impact of this new irradiance record requires the use of coupled atmosphere-ocean general circulation models (GCMs). Nevertheless, our record is already compatible with a global cooling of about $0.5-1{ }^{\circ} \mathrm{C}$ during the "little ice age", and with a general cooling trend during the past millenium followed by global warming during the 20th century (Mann et al., 1999).
\end{abstract}

\section{Solar irradiance variations}

A positive relationship is now well established between the 11-year cycle of solar magnetic activity and the output of the sun (Willson and Hudson, 1988; Willson, 1997). Over the last two 11-year cycles (\#21 and \#22), the amplitude of these fluctations has remained of the order of $0.1 \%$ for the total radiative output. Willson (1997) even proposed that the irradiance increased by $0.04 \%$ between the last 2 minima of solar activity, although this fact has been questioned recently (Fröhlich and Lean, 1998).

Such small fluctuations can only be measured

* Corresponding author.

e-mail: bard@cerege.fr above the atmosphere with spacecraft and data are thus limited to the last 2 decades. This is rather unfortunate, as a direct solar influence has been invoked to explain slow variations of several climatic parameters such as sea level atmospheric pressure (Kelly, 1977), sea surface temperatures (Reid, 1987), equatorial wind patterns (Labitzke and Van Loon, 1988), land air temperatures (FriisChristensen and Lassen, 1991) and strength of cyclogenesis (Tinsley, 1994). Several authors even proposed that the solar variability is responsible for a significant part of the high-frequency component of the natural variability of climate (Eddy, 1976; Lean and Rind, 1994; Lean et al., 1995; Crowley and Kim, 1996; Mann et al., 1998, 1999) and should thus be taken into account when extracting the anthropic influence over the last 
century (Hansen and Lacis, 1990; Kelly and Wigley; 1992).

Astrophysicists have documented simple relationships between magnetic activity and irradiance of the sun (Foukal and Lean, 1990; Lean et al., 1992), and a linear relationship also characterizes sun-like stars (Zhang et al., 1994). These studies have led several workers to use indices of the magnetic variability of the sun as proxy surrogates for irradiance fluctuations. For the last 4 centuries, it has been possible to make use of the record of sunspots observed with telescopes. Most attention has been focused on solar activity minima centred at about 1900, 1810 and $1690 \mathrm{AD}$. The latter is the well-known Maunder minimum (1645-1715 AD) during which almost no sunspots were observed and which coincides with the coldest temperatures of the so-called "little ice age' (Eddy, 1976).

\section{Indirect proxies of the solar irradiance}

A major problem has been the scaling between the sunspot record and the total solar irradiance (TSI). The yearly average sunspot number (SSN) exhibits minimum values which are all similar (Hoyt et al., 1994) and thus a simple linear relationship between SSN and TSI does not allow for long-term variations. Such crude scaling would be inconsistent with long-term fluctuations which have been inferred to exist in the solar magnetic record (Feynman and Crooker, 1978; White et al., 1992; Solanki and Fligge, 1998). In particular, the fact that recent minima of the solar cycle and the Maunder minimum are both characterized by a near absence of sunspots does not necessarily mean that their irradiance was the same as shown by the bimodal distribution of the magnetic activity of sun-like stars (Baliunas and Jastrow, 1990; Lockwood et al., 1992).

Several authors have proposed TSI reconstructions for recent centuries by using different types of information on the solar variability: the envelope of the SSN 11-year cycle (Reid, 1991), the length and decay rate of the solar cycle (Hoyt and Schatten, 1993), the structure and decay rate of individual sunspots (Hoyt and Schatten 1993), the mean level of SSN (Hoyt and Schatten, 1993; Zhang et al., 1994; Reid, 1997), the solar rotation and the solar diameter (Nesme-Ribes et al., 1993), and the geomagnetic aa index (Cliver et al., 1998). Lean et al.
(1995) proposed that the irradiance record could be divided into 2 superimposed components: an 11-year cycle based on the parameterization of sunspot darkening and facular brightening (Lean et al., 1992), and a slowly-varying background derived separately from studies of sun-like stars (Baliunas and Jastrow, 1990). More recently, Solanki and Fligge (1998) reconstructed a solar irradiance record back to $1874 \mathrm{AD}$ by using different relationships for estimating the variations due to solar active regions (quadratic calibration between the SSN and the spacecraft TSI record over a decade) and to the long-term component (linear calibrations between brightness and chromospheric emission or length of the activity cycle).

As illustrated in Fig. 1, these reconstructions exhibit similar fluctuations, but they differ significantly in amplitude. The main differences are best illustrated by comparing the TSI decrease estimated or extrapolated for the deepest part of the Maunder Minimum: 0.24\% (Lean et al. 1995), $0.3 \%$ (Hoyt and Schatten 1993), 0.4\% (Zhang et al., 1994; Solanki and Fligge, 1998), 0.5\% (Nesme-Ribes et al., 1993), 0.54\% (Cliver et al., 1998), 0.65\% (Reid, 1997) and 1\% (Reid, 1991). The estimate by Lean et al. (1995) is often used as a conservative view of TSI changes during the Maunder Minimum. Nevertheless, it should be noted that in the absence of any long-term trend, the TSI reduction during the Maunder Minimum would be of the same $0.1 \%$ magnitude as observed accurately during the 11-year cycle.

There are only few reliable data on the solar variability before the invention of the telescope, which allowed precise sunspot counting (1610 AD). Silverman (1992) compiled the observations of aurora at low and mid-latitudes with the naked eye. This time series reaches the year $1500 \mathrm{AD}$ and clearly shows the most prominent solar minima. However, this record is biased by the number and quality of observations which increases exponentially with time. This makes it difficult to convert this indirect record of the solar magnetic variability into terms of irradiance changes.

\section{Solar modulation of cosmonuclide production}

As a proxy for the solar magnetic variability, it is also possible to use the high-frequency component of the variations in production of cosmogenic 

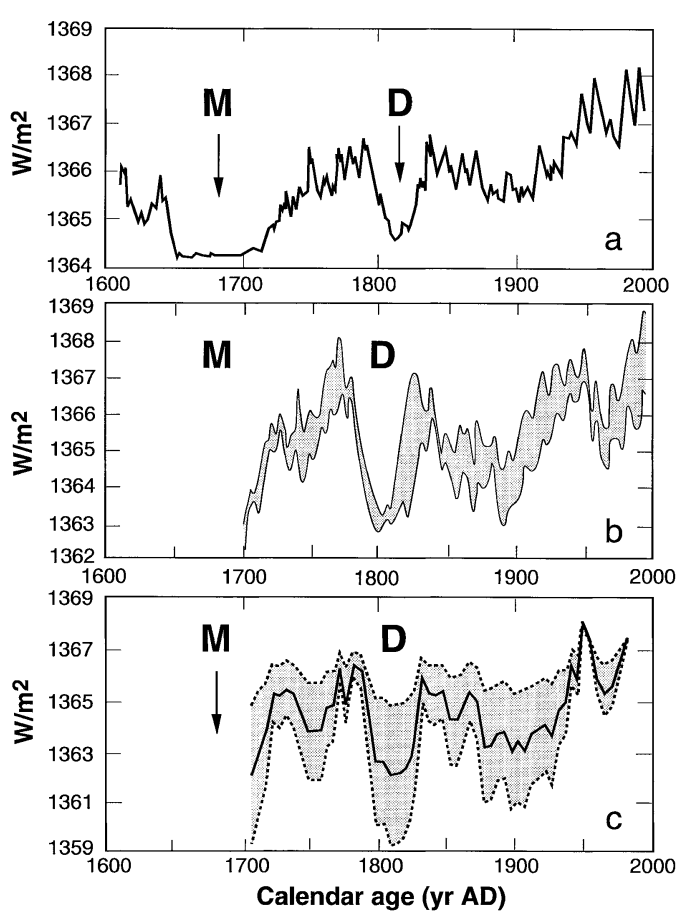

Fig. 1. Published reconstructions of the total solar irradiance (TSI) based on observations of the sun's variability and brightness variations of sun-like stars (see text for the list of proxies used for these reconstructions). The upper panel (1a) is from Lean et al. (1995), the middle panel (1b) is from Hoyt and Schatten (1993) and the lower panel (1c) from Zhang et al. (1994). The scales of the records by Hoyt and Schatten (1993) and Zhang et al. (1994) have been modified to match a modern value of $1367 \mathrm{~W} / \mathrm{m}^{2}$. Note also that, for showing all details, the $y$-axis scales of graphs $1 \mathrm{a}, 1 \mathrm{~b}$ and $1 \mathrm{c}$ are different $\left(5,7\right.$ and $10 \mathrm{~W} / \mathrm{m}^{2}$, respectively).

nuclides such as ${ }^{14} \mathrm{C}$ and ${ }^{10} \mathrm{Be}$ (Lal and Peters, 1967). Magnetic fields of the solar wind deflect the primary flux of charged cosmic particles, which leads to a reduction of cosmogenic nuclide production in the earth's atmosphere. In particular, it has been shown that the 11-year cycle modulates ${ }^{10} \mathrm{Be}$ production recorded in well-dated polar ice from Greenland and Antarctica (Beer et al., 1990; Steig et al., 1996, 1998). Very high cosmonuclide production $(30-50 \%$ above the modern value) was also confirmed for the Maunder Minimum based on high ${ }^{14} \mathrm{C}$ content in tree rings (Stuiver, 1980; Stuiver and Quay, 1980) and ${ }^{10} \mathrm{Be}$ in polar ice (Raisbeck et al., 1981, 1990; Beer et al., 1988).

In a previous contribution (Bard et al., 1997), we compared quantitatively the variations of the atmospheric ${ }^{14} \mathrm{C} /{ }^{12} \mathrm{C}$ ratio, as measured in treerings, with an independent record of the ${ }^{10} \mathrm{Be}$ concentration analysed in well-dated ice from South Pole (Fig. 2a). The ${ }^{14} \mathrm{C}$ and ${ }^{10} \mathrm{Be}$ time series cannot be compared directly, since the fates of these 2 cosmonuclides are different after their production in the atmosphere (see Bard, 1997, 1998, for recent discussions on this issue). In order to quantify this differential effect, we used a numerical box model which, in particular, takes into account the ${ }^{14} \mathrm{C}$ dispersal in major reservoirs of the carbon cycle. The relative fluctuations of ${ }^{10} \mathrm{Be}$ concentrations measured in the South Pole ice core were used as a model input to compute a synthetic atmospheric ${ }^{14} \mathrm{C} /{ }^{12} \mathrm{C}$ record. Fig. $2 \mathrm{~b}$ illustrates that the modelled ${ }^{14} \mathrm{C} /{ }^{12} \mathrm{C}$ variations agree in timing and amplitude with the ${ }^{14} \mathrm{C} /{ }^{12} \mathrm{C}$ data measured in tree-rings at a decadal resolution. In particular, it is straightforward to identify, in both records, periods of maximum ${ }^{14} \mathrm{C} /{ }^{12} \mathrm{C}$ corresponding to known solar activity minima centred at about 1900, 1830 (Dalton) and $1690 \mathrm{AD}$ (Maunder). This close agreement confirms the quality of the record of cosmonuclide production used as a model input as well as its reliability in simulation of the solar modulation.

\section{A new irradiance record for the last millenium}

The concomitant production variations of ${ }^{14} \mathrm{C}$ and ${ }^{10} \mathrm{Be}$ can be used as a proxy for the TSI by assuming a linear relationship between magnetic activity and irradiance following previous workers (Lean et al., 1992; Zhang et al., 1994; Solanki and Fligge, 1998). Fig. 3a,b present TSI curves computed by first smoothing the cosmonuclide production record and then applying a linear scaling using the TSI values published previously for the Maunder Minimum (see discussion above). These data are available in numerical form as supplementary information and at http://www.cerege.fr/.

Smoothing the record is necessary to remove the meteorological "noise" which is partly responsible for the decadal variability of the raw ${ }^{10} \mathrm{Be}$ record (Fig. 2a). This short-term variability disappears when considering the ${ }^{14} \mathrm{C}$ time series (i.e., Fig. 2b), because the carbon cycle acts as a low pass filter (both in nature and in the modelling 

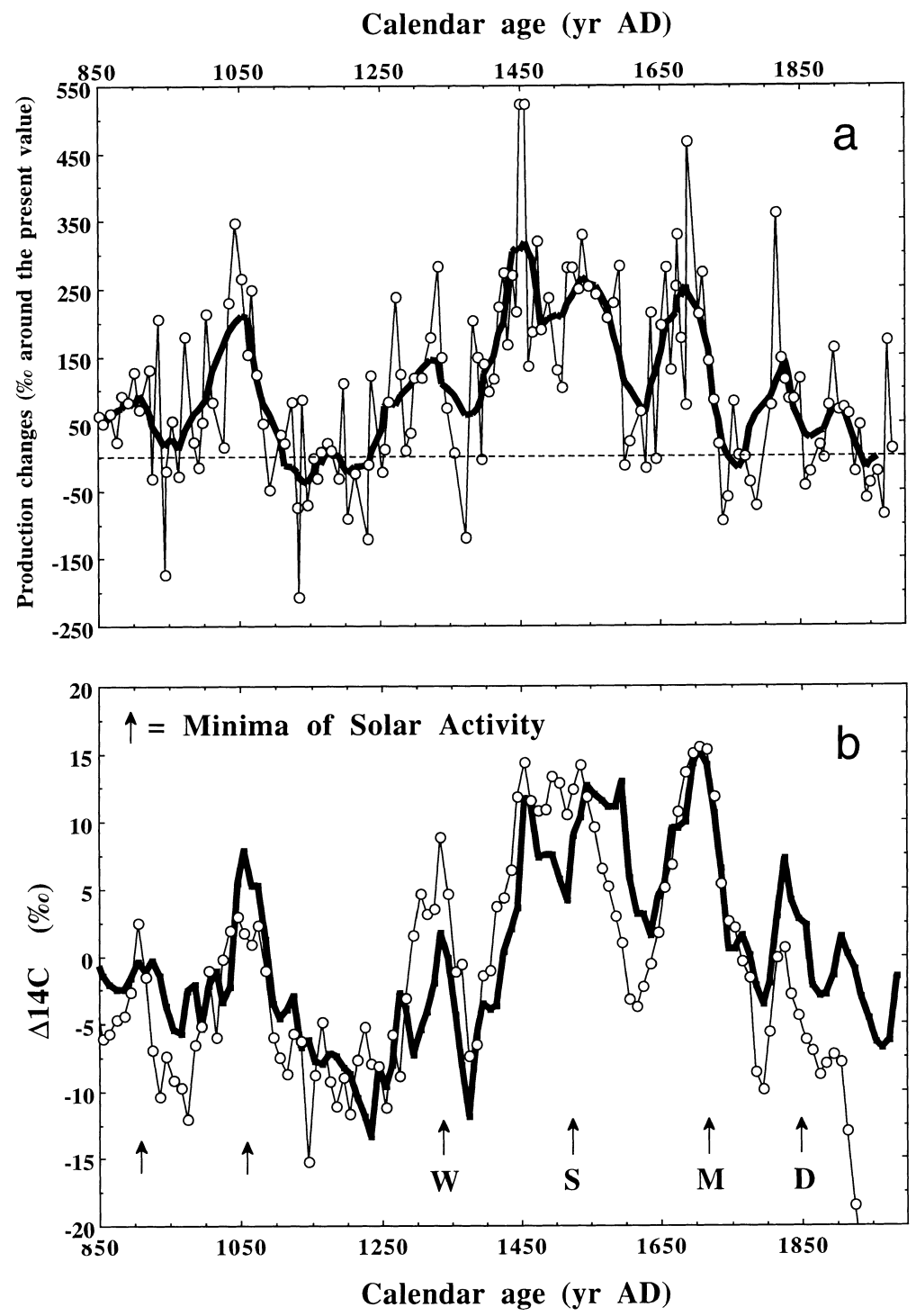

Fig. 2. The upper panel (2a) shows the record of the cosmonuclide production (\%o variations around the present value) during the last millenium as reconstructed from the ${ }^{10} \mathrm{Be}$ concentration measurements in South Pole ice (Raisbeck et al., 1990) and the quantitative comparison with the atmospheric ${ }^{14} \mathrm{C} /{ }^{12} \mathrm{C}$ record (Bard et al., 1997). Dots show the raw production record and the solid line a smoothed curve obtained with a Gaussian filter. The lower panel (2b) shows with open dots the detrended ${ }^{14} \mathrm{C} /{ }^{12} \mathrm{C}$ record measured in tree rings (Stuiver, 1980). The solid curve shows the tropospheric ${ }^{14} \mathrm{C} /{ }^{12} \mathrm{C}$ variations simulated by using a 12 box model and the relative production changes shown in the upper panel. The ${ }^{14} \mathrm{C} /{ }^{12} \mathrm{C}$ values are represented as \%o variations $\left(\Delta^{14} \mathrm{C}\right)$.

exercise). Further analysis of ${ }^{10} \mathrm{Be}$ in ice cores from different sites in Antarctica will be necessary to distinguish the short-term global production variability from the local meteorological fluctuations.
In particular, a higher resolution would be required in order to test the recent claim by Beer et al. (1998) that the 11-year solar cycle did not completely cease during the Maunder Minimum. 

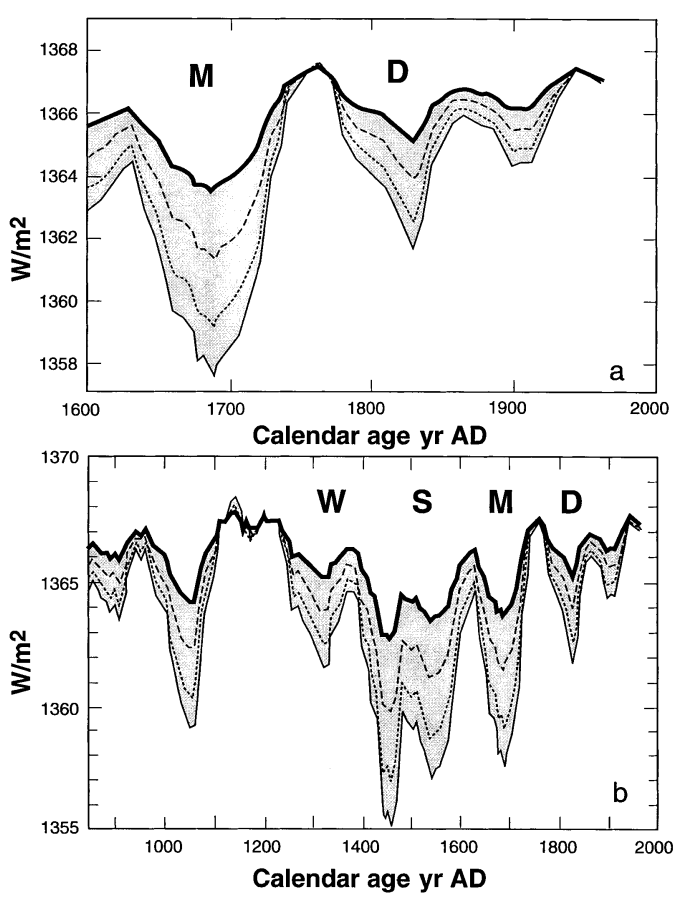

Fig. 3. TSI reconstructions based on the smoothed cosmonuclides production record. The upper panel (3a) shows the last 4 centuries and can be compared directly with Fig. 1. The lower panel ( $3 \mathrm{~b})$ presents the record for the last 1200 years. The different curves have been obtained with different scaling factors to match the Maunder Minimum irradiance reduction derived by previous authors: thick lines $(0.25 \%$, Lean et al., 1995), dashed lines $(0.4 \%$, Zhang et al., 1994; Solanki and Fligge, 1998), dotted lines (0.55\%, Cliver et al., 1998) and thin lines $(0.65 \%$, Reid, 1997). The shaded area is bracketed by the low and high TSI estimates based on the factors derived from Reid (1997) and Lean et al. (1995), respectively. This latter curve is highlighted by a thick line as it constitutes a rather plausible alternative for extending the solar irradiance over the last millenium (see Section 2 for details).

Over the last 4 centuries, our irradiance reconstruction is in reasonable agreement with independent reconstructions based on observations of the sun (Fig. 1). The extended TSI record suggests that the solar output was significantly reduced between 1450 and $1850 \mathrm{AD}$, but slightly higher or similar to the present value during a period centred around $1200 \mathrm{AD}$. It could thus be argued that irradiance variations may have contributed to the so-called "little ice age" (about 1500 to $1750 \mathrm{AD}$ ) and "medieval warm period" (about 900 to
$1400 \mathrm{AD}$ ), although the timing and signatures of these two climatic events are still debatable (Bradley and Jones, 1993; Hughes and Diaz, 1994; Dahl-Jensen et al., 1998). Indeed, some researchers have concluded that the "little ice age" and/or "medieval warm period" are regional, rather than global events (see description and discussion of spatial and temporal details in Bradley and Jones, 1993 and Hughes and Diaz, 1994). At first sight, TSI variations would not be a likely mechanism, for it would tend to force global effects. However, general circulation modelling of the atmospheric response to a TSI reduction by $0.25 \%$ clearly indicates that not every locale experiences cooling, as advective changes in the atmosphere can dominate the radiative cooling (Lean and Rind, 1994). This regional variability of the response could even be greater by taking into account the advective changes of the ocean.

As shown by many studies (Lean, 1989; 1991; Lean et al., 1995), the irradiance variations are not spectrally averaged, and the relative amplitude of the UV variability is an order of magnitude larger than the total irradiance changes. Haigh (1994, 1996) has even shown that the climatic response is enhanced by a positive feedback due to stratospheric ozone: the stratosphere is heated, because there is excess UV radiation absorbed by ozone and because the ozone formation is favoured through photochemical reactions (Gille et al., 1984). In addition, the time series of the cosmonuclide production may provide additional climatic information if a direct link between cosmic rays, droplet nucleation and cloud cover is confirmed (Tinsley, 1994; Svensmark and FriisChristensen, 1997).

It is clear that the exact implications of our irradiance reconstruction in terms of global and regional climate must be evaluated by means of GCMs, taking into account these atmospheric feedbacks and also the memory effect of the seasurface heating. Such results were obtained by Cubasch et al. (1997) for the last 3 centuries, based on the TSI record presented in Fig. 1b (Hoyt and Schatten, 1993). For the millenium-long record, it will be interesting to evaluate whether the distinct periods of reduced TSI between 1250 and $1750 \mathrm{AD}$ could explain part of the general cooling trend which followed the 14th century (Mann et al., 1999). Nevertheless, it is already possible to calculate a 1st-order global climatic response which 
strongly depends on the overall amplitude of the irradiance variations. For the period between 1400 and $1600 \mathrm{AD}$, a midrange total irradiance decrease of $0.35 \%$ corresponds to a decrease of about $4.8 \mathrm{~W} / \mathrm{m}^{2}$ in total irradiance $(1367 \times 0.35 / 100)$. This leads to $0.84 \mathrm{~W} / \mathrm{m}^{2}$ when averaged over the whole earth's surface, assuming an albedo of 0.3 $(4.8 \times 0.7 / 4)$. At equilibrium, this would lead to a cooling between 0.2 and $0.8^{\circ} \mathrm{C}$ in typical GCMs characterized by sensitivities between 0.25 and $0.95^{\circ} \mathrm{C} \mathrm{W}^{-1} \mathrm{~m}^{2}$ (Myrhe et al., 1998).

\section{Conclusions and perspectives}

Based on 2 independent but concordant cosmogenic isotope records, we propose a reliable solar index for the last 1200 years. This new record agrees with those previously published for the last 3 centuries based on direct observations of the sun's surface. The main outcome of our study is that the solar magnetic activity, and thus the TSI, was usually lower than present during most of the last millenium, except during a brief period centred around $1200 \mathrm{AD}$. This solar variability record is qualitatively similar to the climate reconstruction proposed recently by Mann et al. (1999), suggesting that the 20th century warming followed a millenial-scale cooling trend.

Conversion of the new solar variability record in terms of TSI is attempted by means of linear scaling factors. As illustrated by the shaded zone in Fig. 3, this simple approach leads to a TSI spread which is a direct consequence of the rather large range of values deduced by previous authors for the Maunder Minimum. As described in Section 2, these estimates are not always independent, because some of them are based on stellar observations, some on other physical arguments and some even from the expected climatic record of the earth.

Further improvements in the TSI quantification could be expected as progress will be made on physical mechanisms defining the nature of longterm components of the solar variability. It will also depend on improvements in estimating the correlation between TSI and solar magnetic activity. A direct way of doing this would be to compare ${ }^{10} \mathrm{Be}$ production during recent solar minima with production during the Maunder Minimum in the same core from Antarctica as described by Raisbeck and Yiou (1980). Such a calibration cannot be done with ${ }^{14} \mathrm{C}$ both because of the strong damping of the 11-year production cycle and the interference of the Suess effect (during the 20 th century the measured atmospheric $\Delta{ }^{14} \mathrm{C}$ can no longer be used to accurately study the natural variations, since the ${ }^{14} \mathrm{C}$ atmospheric concentration has been significantly decreased by the anthropic combustion of ${ }^{14} \mathrm{C}$-dead fossil fuels).

\section{Acknowledgements}

We thank J.-J. Motte for drawings. This research is supported by CNRS, IN2P3, CEA and EC grant MilEClim ENV4-CT97-0659.

\section{REFERENCES}

Baliunas, S. and Jastrow, R. 1990. Evidence for longterm brightness changes of solar-type stars. Nature 348, 520-522.

Bard, E. 1997. Nuclide production by cosmic rays during the Last Ice Age. Science 277, 532-533.

Bard, E. 1998. Geochemical and geophysical implications of the radiocarbon calibration. Geochimica Cosmochimica Acta 62, 2025-2038.

Bard, E., Raisbeck, G., Yiou, F. and Jouzel, J. 1997. Solar modulation of cosmogenic nuclide production over the last millenium: comparison between ${ }^{14} \mathrm{C}$ and ${ }^{10} \mathrm{Be}$ records. Earth Planet. Sci. Lett. 150, 453-462.

Beer, J., Tobias, A. and Weiss, B. 1998. Solar Physics 181, 237-249.

Bradley, R. S. and Jones, P. D. 1993. "Little Ice Age" summer temperature variations: their nature and relev- ance to recent global warming trends. The Holocene 3, 367-376.

Beer, J., Siegenthaler U., Bonani, G., Finkel, R. C., Oeschger, H., Suter, M. and Wölfli, W. 1988. Information on past solar activity and geomagnetism from ${ }^{10} \mathrm{Be}$ in the Camp Century ice core. Nature 331, 675-679.

Beer, J., Blinov, A., Bonani, G., Finkel, R. C., Hofmann, H. J., Lelmann, B., Oeschger, H., Sigg, A., Schwander, J., Staffelbach, T., Stauffer, B., Suter, M. and Wölfli, W. 1990. Use of ${ }^{10} \mathrm{Be}$ in polar ice to trace the 11-year cycle of solar activity. Nature 347, 164-166.

Cliver, E. W., Boriakoff, V. and Feynman, J. 1998. Solar variability and climate change: geomagnetic and aa index and global surface temperature. Geophys. Res. Lett. 25, 1035-1038. 
Crowley, T. J. and Kim, K.-Y. 1996. Comparison of proxy records of climate change and solar forcing. Geophys. Res. Lett. 23, 359-362.

Cubash, U., Voss, R., Hegerl, G. C., Waszkewitz, J. and Crowley, T. J. 1997. Simulation of the influence of solar radiation variations on the global climate with an ocean-atmosphere general circulation model Climate Dynamics 13, 757-767.

Dahl-Jensen, D., Mosegaard, K., Gundestrup, N., Clow, G. D., Johnsen, S. J., Hansen, A. W. and Balling, N. 1998. Past temperatures directly from the Greenland ice sheet. Science 282, 268-271.

Eddy, J. A. 1976. The Maunder minimum. Science 192, 1189-1202.

Feynman, J. and Crooker, N. U. 1978. The solar wind at the turn of the century. Nature 275, 626-627.

Foukal, P. and Lean, J. 1990. An empirical model of total solar irradiance variation between 1874 and 1988 . Science 247, 556-558.

Friis-Christensen, E. and Lassen, K. 1991. Length of the solar cycle: an indicator of solar activity closely associated with climate, Science 254, 698-700.

Fröhlich, C. and Lean, J. 1998. The Sun's total irradiance: cycles, trends and related climate change uncertainties since 1976. Geophys. Res. Lett. 25, 4377-4380.

Gille, J. C., Smythe, C. M. and Heath, D. F. 1984. Observed ozone response to variations in solar ultraviolet radiation. Science 225, 315-317.

Hansen, J. E. and Lacis, A. A. 1990. Sun and dust versus greenhouse gases: an assessment of their relative roles in global climate change, Nature 346, 713-719.

Hoyt, D. V. and Schatten, K. H. 1993. A discussion of plausible solar irradiance variations, 1700-1992. J. Geophys. Res. 98 (A11), 18,895-18,906.

Hoyt, D. V., Schatten, K. H. and Nesme-Ribes, E. 1994 The one hundredth year of Rudolf Wolf's death: do we have the correct reconstruction of solar activity. Geophys. Res. Lett. 21, 2067-2070.

Haigh, J. D. 1994. The role of stratospheric ozone in modulating the solar radiative forcing of climate. Nature 370, 544-546.

Haigh, J. D. 1996. The impact of solar variability on climate. Science 272, 981-984.

Hughes, M. K. and Diaz, H. F. (eds.). 1994. The Medieval Warm Period. Climatic Change 26, 1-317.

Kelly, P. M. 1977. Solar influence on North Atlantic mean sea level pressure. Nature 269, 320-322

Kelly, P. M. and Wigley, T. M. L. 1992. Solar cycle length, greenhouse forcing and global climate. Nature 360, 328-330.

Labitzke, K. and Van Loon, H. 1988. Associations between the 11-year solar cycle, the QBO and the atmosphere (I). The troposphere and stratosphere in the northern hemisphere winter. J. Atmos. Terr. Phys. 50, 197-206.

Lal, D. and Peters, B. 1967. Cosmic ray produced radioactivity on the Earth. In: Handbuch der Physik, XLVI 2. Springer, Berlin, pp. 551-612.
Lean, J. 1991. Variations in the Sun's radiative output. Rev. Geophys. 29, 505-535.

Lean, J. and Rind, D. 1994. Solar variability: implications for global change. $\operatorname{EOS~75,1-6.~}$

Lean J., Skumanich, A. and White, O. 1992. Estimating the Sun's radiative output during the maunder minimum. Geophys. Res. Lett. 19, 1591-1594.

Lean, J., Beer, J. and Bradley, R. 1995. Reconstruction of solar irradiance since 1610: implications for climate change. Geophys. Res. Lett. 22, 3195-3198.

Lockwood, G. W., Skiff, B. A., Baliunas, S. L. and Radick, R. R. 1992. Long-term solar brigthness changes estimated from a survey of Sun-like stars. Nature 360, 653-655.

Mann, M. E., Bradley, R. S. and Hughes, M. K. 1998 Global-scale temperature patterns and climate forcing over the past six centuries. Nature 392, 779-787.

Mann, M. E., Bradley, R. S. and Hughes, M. K. 1999 Northern Hemisphere temperatures during the past millenium: inferences, uncertainties and limitations. Geophys. Res. Lett. 26, 759-762.

Myhre, G., Highwood, E. J., Shine, K. P. and Stordal, F. 1998. New estimates of radiative forcing due to well mixed greenhouse gases. Geophys. Res. Lett. 25, 14, 2715-2718.

Nesme-Ribes, E., Ferreira, E. N., Sadourny, R., Le Treut, H. and Li, Z. X. 1993. Solar dynamics and its impact on solar irradiance and the terrestrial climate. J. Geophys. Res. 98, A11, 18,923-18,935.

Raisbeck, G. M. and Yiou, F. $1980 .{ }^{10} \mathrm{Be}$ in polar ice cores as a record of solar activity, In: Proceedings, Conference on the ancient sun (eds. Pepin, R. O., Eddy, J. A. and Merril, R. B.). Pergamon, New-York, pp. $185-190$.

Raisbeck, G. M., Yiou, F., Fruneau, M., Loiseaux, J. M., Lieuvin, M., Ravel, J. C. and Lorius, C. 1981. Cosmogenic ${ }^{10} \mathrm{Be}$ concentrations in Antarctic ice during the past 30,000 years. Nature 292, 825-826.

Raisbeck, G. M., Yiou, F., Jouzel, J. and Petit, J.-R. 1990. ${ }^{10} \mathrm{Be}$ and ${ }^{2} \mathrm{H}$ in polar ice cores as a probe of the solar variability's influence on climate. Phil. Trans. Roy. S. Lond. A300, 463-470.

Reid, G. C. 1987. Influence of solar variability on global sea surface temperatures. Nature 329, 142-143.

Reid, G. C. 1991. Solar total irradiance variations and the global sea surface temperature record. J. Geophys. Res. 96, D2, 2835-2844.

Reid, G. C. 1997. Solar forcing and global climate change since the mid-17th century. Climatic Change 37, 391-405.

Silverman, S. M. 1992. Secular variation of the aurora for the past 500 years. Rev. Geophys. 30, 333-351.

Solanki, S. K. and Fligge, M. 1998. Solar irradiance since 1874 revisited. Geophys. Res. Lett. 25, 341-344.

Steig, E. J., Polissar, P. J., Stuiver, M., Grootes, P. M. and Finkel, R. C. 1996. Large amplitude solar modulation cycles of ${ }^{10} \mathrm{Be}$ in Antartica: implications for atmospheric mixing processes and interpretation of the ice core record. Geophys. Res. Lett. 23, 523-526. 
Steig, E. J., Morse, D. L., Waddington, E. D. and Polissar, P. J. 1998. Using the sunspot cycle to date ice cores Geophys. Res. Lett. 25, 163-166.

Stuiver, M. 1980. Solar variability and climatic change during the current millennium. Nature 286, 868-871.

Stuiver, M. and Quay, P. D. 1980. Changes in atmospheric Carbon-14 attributed to a variable sun. Science 207, 11-19.

Svensmark, H. and Friis-Christensen, E. 1997. Variations of cosmic ray flux and global cloud coverage - a missing link in solar-climate relationships. J. Atm Solar-Terrest. Phys. 59, 1225-1232.

Tinsley, B. A. 1994. Solar wind mechanism suggested for weather and climate change, EOS 75, 369-374.
White, O. R., Skumanich, A., Lean, J., Livingston, W. C. and Keil, S. L. 1992. The sun in a noncycling state. Publ. Astron. Soc. Pac. 104, 1139-1143.

Willson, R. C. 1997. Total solar irradiance trend during solar cycles 21 and 22. Science 277, 1963-1965.

Willson, R. C. and Hudson, H. S. 1988. Solar luminosity variations in solar cycle 21. Nature 332, 810-812.

Zhang Q., Soon, W. H., Baliunas, S. L., Lockwood, G. W., Skiff, B. A. and Radick, R. R. 1994. A method of determining possible brightness variations of the sun in past centuries from observations of solar-type stars. Astrophys. J. 427, L111-L114. 